\title{
Gutenberg 2018. Cómo se forjó la cultura del diseño
}

RECIBIDO: 06.02.2018 / ACEPTADO: 05.03.2018

\section{Resumen}

Con motivo del 550 aniversario de la muerte de J. Gutenberg, como referente clave de la cultura occidental y el progreso, se presenta esta reseña que analiza su trayectoria desde la aproximación a la técnica de la imprenta tipográfica que revolucionó nuestra sociedad. En este sentido, se analizan la evolución del término diseño a partir del griego, se presenta el carácter multidisciplinar del libro impreso y su condición de obra múltiple, y se fundamenta y defiende el término global grafismo como la disciplina que abarca todo el ámbito del Dibujo (figurativo, geométrico, abstracto), de la Escritura (el código del alfabeto latino) y del Esquema (la geometría de lo invisible).

Palabras claves: Gutenberg, imprenta tradicional, libro, diseño, grafismo, multidisciplinariedad.

\section{Gutenberg 2018. How the design culture was forged}

\begin{abstract}
On the occasion of the 550th anniversary of the death of J. Gutenberg, as a key reference of occidental culture and progress, this review is presented among the articles that make up this issue. Its author is the specialist who has contributed the most to the theory and development of the discipline of design in the Spanish language, with more than forty published books, and a regular collaborator. The review begins an approach to the typographic printing technique that revolutionized our society. In this sense, the evolution of the term design from the Greek is analyzed, the multidisciplinary character of the printed book and its original multiple work condition is presented, and the global term graphism is founded and defended as the discipline that covers the whole field of Drawing (figurative, geometric, abstract), of the Scripture (the Latin alphabet code) and of the Scheme (the geometry of the invisible).
\end{abstract}

Keywords: Gutenberg, traditional printing, book, design, graphics, multidisciplinarity. 
El sábado 3 de febrero de 2018 Europa conmemoró el legado revolucionario de la imprenta tipográfica y el 550 aniversario de la muerte de Gutenberg, personaje clave en la historia de la cultura y el progreso.

Los diseñadores gráficos y todos los que amamos el arte gráfico y las disciplinas que derivan de él, deberíamos sentirnos concernidos. Porque allí está el origen de nuestra cultura profesional.

Los editores internacionales y gente del libro en general que acudieron a la Feria del Libro de Frankfurt en esta fecha, estaban al tanto de que, hay un tren en la cercana estación central, y tras un trayecto de apenas veinte minutos, pudieron ir a parar en el lugar donde está el origen de su oficio: en Maguncia (Mainz), la localidad natal de Johannes Gutenberg, hijo de una familia de orfebres y metalúrgicos, cuyo oficio le dio la idea de la invención tipográfica. Tipografía es, literalmente, escritura con tipos. En Maguncia está el Museo Gutenberg.

Sabemos mucho de la tipografía, del arte gráfico, del grafismo y de las artes del libro. Existe una cantidad apabullante de artículos, libros, monografías y documentos sobre la tipografía. Pero quizás son pocos los que pueden decir con toda propiedad por qué la tipografía gutenberguiana fue el embrión del diseño gráfico, tal como entendemos hoy esta disciplina.

\section{La semilla del diseño}

La invención de la tipografía, en 1450, es contemporánea de la aparición de una palabra engañosa: diseño. Digo "engañosa" porque venía del griego de signum, de ahí pasó a Italia y a través del latín disegno, llegó a España. Esta palabra, aunque en italiano se pronuncia "diseño", como en español, no significa diseño, sino "dibujo". La prueba es que la lengua italiana incluye la palabra "dibujo" (disegno), pero no tiene el equivalente de "diseño". Por eso utiliza el inglés design.

Observemos que el griego de signum incluye el término signum (signo), que significa, al mismo tiempo, "signo" y "dibujo". En español, la raíz design está también en la palabra designio, que es sinónimo de "proyecto". Esta clave es fundamental. Nos recuerda que el sentido de proyecto es la matriz de la palabra diseño. El sentido proyectual del término es realmente "el alma del diseño". En todas sus disciplinas y variantes.

\section{Un arte multidisciplinar}

La invención de la imprenta tipográfica fue una síntesis de la mentalidad técnica, que sería el germen pionero de la cultura industrial del siglo XVIII. La mentalidad técnica gutenberguiana ya era multidisciplinar, y así incluyó los trabajos de autores de textos (historiadores, literatos, poetas y fuentes tradicionales); los aspectos del grafismo (dibujo de los caracteres, las familias tipográficas, las cifras, los signos de puntuación, las letras ornadas, viñetas, ilustraciones y la pauta para la compaginación); la carpintería y la metalurgia (para el torno); la fundición (para los tipos de plomo); la química (para la fabricación de la tinta y del papel).

En esta gran movida, los artistas gráficos, grabadores, dibujantes, ilustradores y calígrafos, acudieron entusiasmados a la llamada de Gutenberg. La idea no les era extraña del todo, porque en aquella época 
renacentista, todos ellos eran grabadores y conocían bien la estampa, la estampación, es decir, el sistema de la copia múltiple, una propiedad que no existía en ninguna otra forma de arte (arquitectura, escultura, pintura). Pero esta misma propiedad múltiple del grabado había desprestigiado el arte del dibujo en el mundo de las Bellas Artes, considerándolo arte menor precisamente por el hecho de ser múltiple. En aquel tiempo, el Arte, el gran arte, tenía que ser obra única e irrepetible, con su hic et nunc, es decir, su unicidad, que sólo podía estar en un sitio aquí y ahora. Esta condición de pieza única era considerada un valor supremo del Arte.

Los artistas gráficos, acostumbrados al inmenso campo de libertad que el arte les ofrecía, acudieron gustosamente a la causa de Gutenberg y se adaptaron a las exigencias de la técnica. Así fue cómo se afirmaron los tres lenguajes gráficos fundamentales: la Imagen, el Signo y el Esquema, es decir, las ilustraciones librescas, el dibujo de tipos de letra y la pauta de diagramación, la proporción áurea que incorporaba al libro la belleza geométrico-matemática. El aporte de los artistas gráficos a la imprenta tipográfica es lo que hemos llamado el "lenguaje bi-media" (imagen-texto) pero monocanal en la percepción visual. Ese lenguaje que articula imágenes y textos venía de lejos y era obra del arte combinatoria de Ramon Llull, y las miniaturas del siglo XIII. La combinatoria luliana es el centro de la creatividad. Y la combinatoria gutenberguiana imagen-texto está en la base del diseño gráfico, todavía hoy.

El sublenguaje del Color no era técnicamente posible en tiempos de Gutenberg y por eso los libros eran impresos en negro sobre blanco. Es curioso que todas las técnicas derivadas de la imagen hayan empezado así: no sólo la tipografía, sino también la fotografía, el cine y la televisión. Primero fueron incoloras.

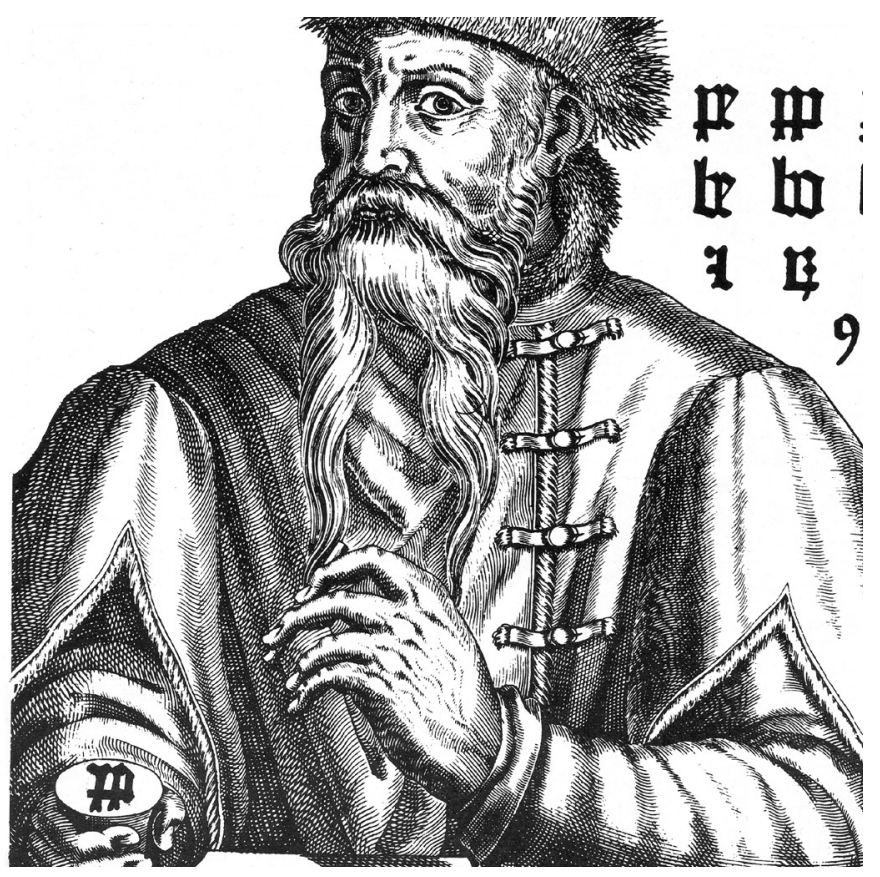

Fig. 1 Primer retrato de Gutenberg. A la derecha, se agregaron algunas de sus abreviaciones y logotipos en letras ligadas, a lo cual corresponde el punzón retocado que él sostiene en la mano. 


\section{Graphein}

El origen de todo esto tenía un nombre griego: Graphein, que traducimos por grafismo. El grafismo gutenberguiano todavía no era diseño, pero fue su embrión. La sabiduría griega se había anticipado, sin saberlo, a lo que fue la sangrienta gran batalla ideológica del Escrito contra la Imagen, como si fueran el Bien contra el Mal. Esa idea llevó al enfrentamiento feroz de los iconoclastas, enemigos de las imágenes, y los iconófilos, sus defensores. Una guerra que duró de 717 al 842 . El Antiguo testamento había prohibido explícitamente producir imágenes, y esa guerra entre las imágenes como falsas y engañosas que querían suplantar la realidad, y el escrito como producto del pensamiento puro y de la verdad, fue determinante de la conformación del pensamiento europeo.

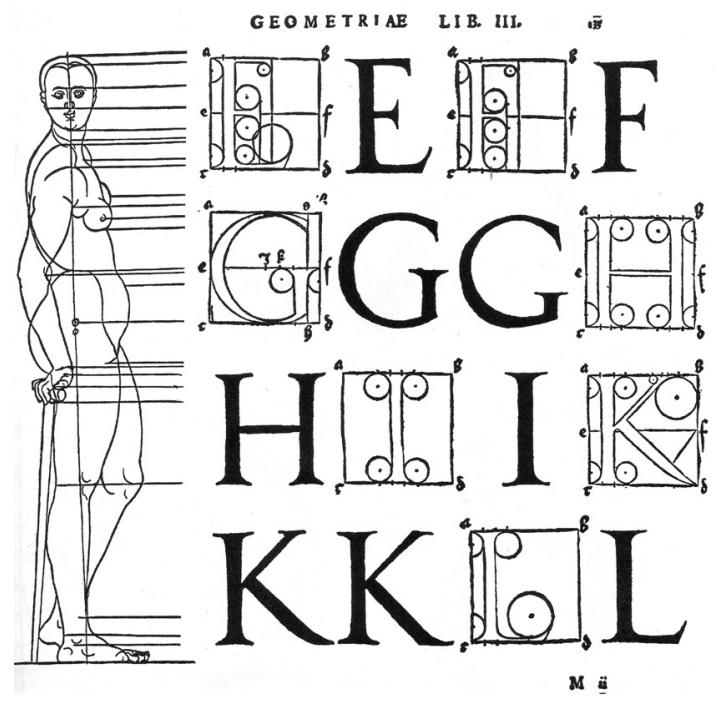

Fig. 2. A. Durero. Diseño de caracteres tipográficos en base a las proporciones del cuerpo humano (1528).

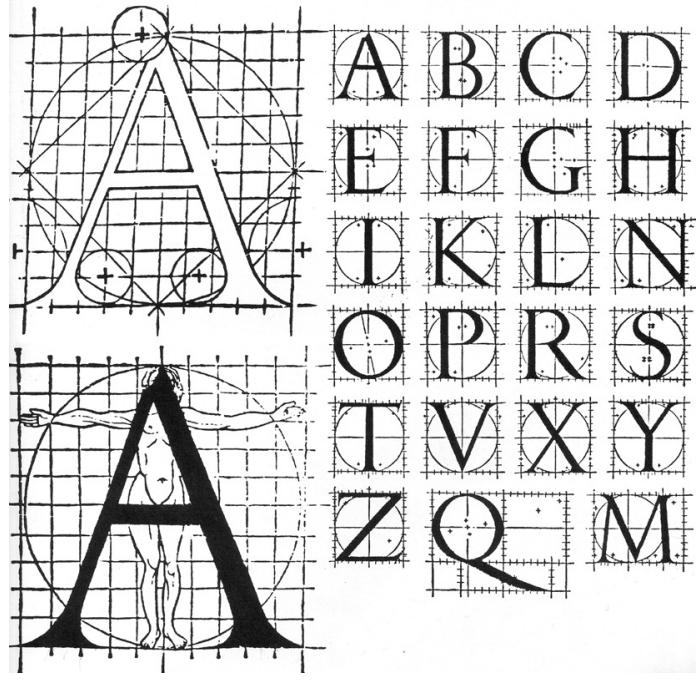

Fig. 3. Las capitales, obra de Geofroy Tory (1529).

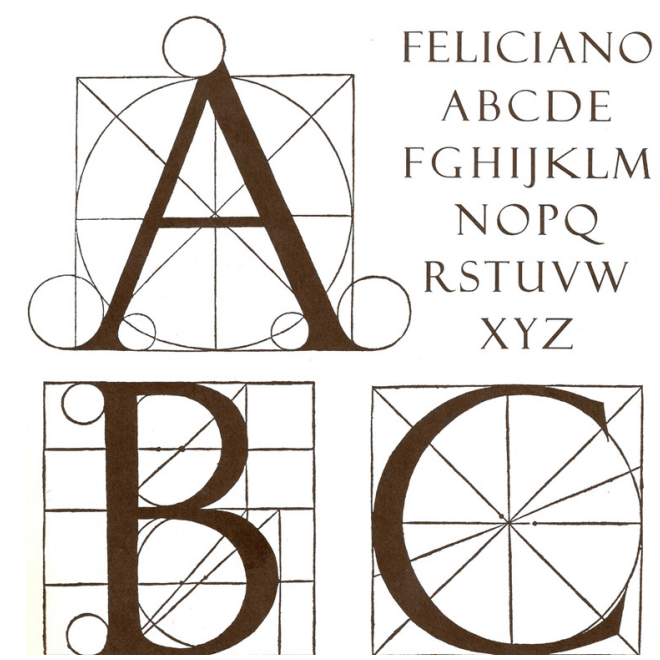

Fig. 4. Felice Feliciano, calígrafo inspiró el "Alphabeto" dignissimo antico de Luca Paccioli (1509). 
Los sabios griegos habían negado toda contradicción o conflicto entre las imágenes y lo escrito. "La mano que escribe es la misma que dibuja". La expresión grafismo abarca todo el universo de "lo gráfico". Y lo gráfico -el Grafismo- es el ámbito del Dibujo (figurativo, geométrico, abstracto), de la Escritura (el código del alfabeto latino) y del Esquema (la geometría de lo invisible).

Los grafistas gutenberguianos se acomodaron al rigor técnico, a las exigencias del medio, y artistas célebres como Urs, Graf, Holbein o Dürer dibujaron familias tipográficas de las que ellos mismos crearon las reglas canónicas, de las que la escritura manual carecía. Las bases geométricas y matemáticas de la proporcionalidad estaban en el dibujo de cada letra, de cada signo...

\section{La materia del grafismo}

La materia del grafismo, aquello que lo hace trazable, manejable y visible, es la Línea. La sequedad mínima de la línea -ella misma abstracción pura que emerge del gesto, energía biológica-, ella, con sus arabescos, sus garabatos, sus trazos y sus trazados. Negro sobre blanco. En la hoja de papel, el lápiz fija un punto y hace fluir la línea, que se convierte en letra, en pájaro, en laberinto... El filósofo alemán Walter Benjamin habla de línea gráfica, línea de la escritura, línea de la geometría y línea del signo absoluto (el arte). La línea dibuja también la estructura de las cosas invisibles que están en el entorno y en el propio pensamiento: los esquemas.

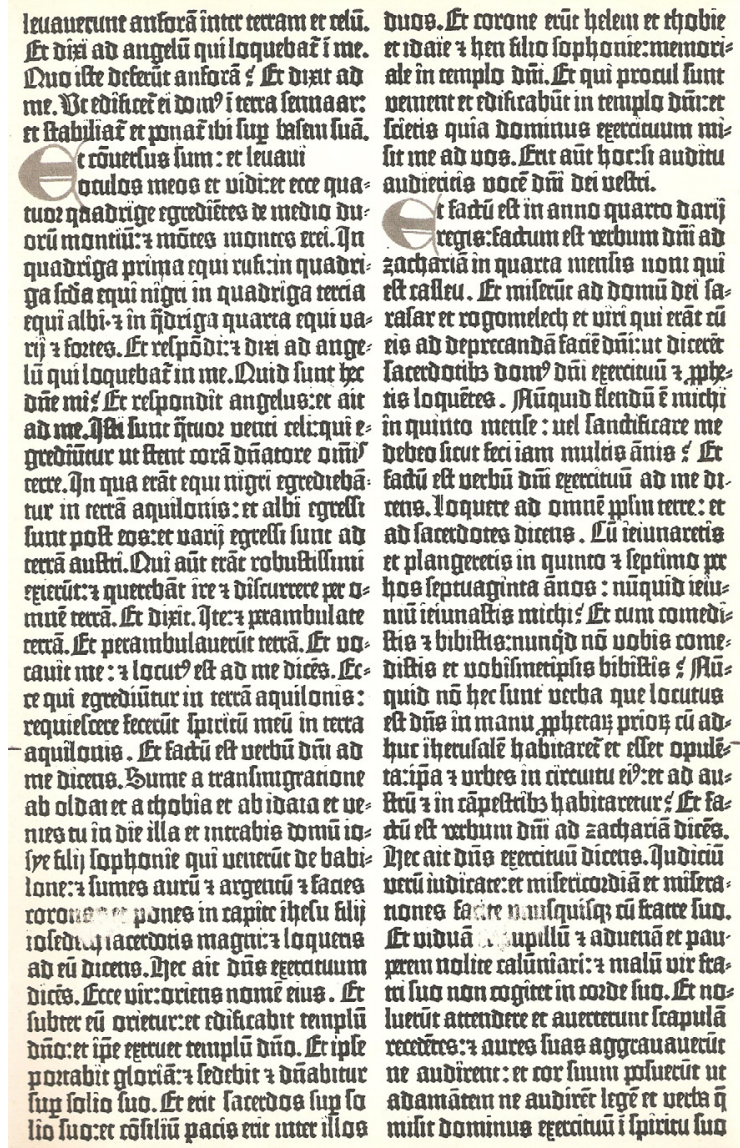

Fig. 5. Gutenberg, Biblia de 42 líneas. 
El primer libro impreso por Gutenberg fue la famosa Biblia de 42 líneas, en referencia a las líneas de texto por página. La Iglesia alemana fue la primera clienta de la obra gutenberguiana. La Biblia que le encargó, tendría que parecer escrita a mano, y para realizar ese deseo tuvieron que fabricarse trescientos caracteres.

Gutenberg era un humanista y el encargo de que la Biblia pareciese caligrafiada le hizo pensar. Cómo hacer que la fragmentación mecánica del sistema tipográfico, hecho letra a letra, signo a signo, pudiera parecerse a la letra ligada de la escritura que fluye espontánea de la mano. Encontró la idea en las abreviaturas: et, etc. y otras. Esas letras ligadas podían darse en una sola unidad tipográfica, un solo punzón y una misma fundición en plomo, es decir, un solo "tipo". Siguiendo esta lógica, estudió aquellas palabras que repiten unas mismas letras juntas. Pongámoslo en español: la letra $q$ va seguida de una $u$, y luego vienen generalmente una $e$ o una $i$ (queso, quien), entonces, que y qui podían ser unidas tipográficamente en tipos compuestos de tres letras ligadas. Así fueron dibujados estos conjuntos, que además de introducir ligaduras en los textos, imitando el manuscrito, ahorraban tiempo a los tipógrafos y cajistas, que componían las páginas signo a signo, buscados en sus cajetines correspondientes, y después de imprimir regresarlos de nuevo allí. Además, Gutenberg hizo dibujar letras para finales de los párrafos con trazos libres, rasgueos y arabescos que recordaban la escritura manual, y los adornos y acabados de la caligrafía.

Gutenberg quiso darles un nombre a esas letras ligadas. Si cada "tipo" se llama así porque cada signo alfabético tiene una forma (un tipo) diferente; y si cada tipo es un signo del alfabeto; entonces esos tipos ligados en uno no provenían del alfabeto sino que (como hemos visto con las abreviaturas y los fragmentos de palabras) venían de las palabras. Del griego logos, que significa palabra, discurso, Gutenberg tomó el prefijo y le añadió el sufijo -tipo: acababa de inventar los logotipos.

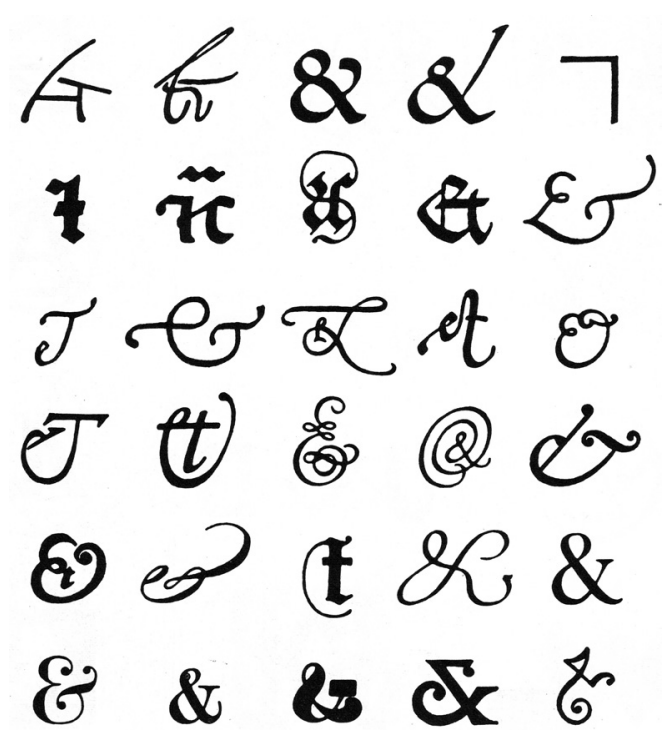

Fig. 6. Abreviaturas que inspiraron los logotipos gutenberguianos.

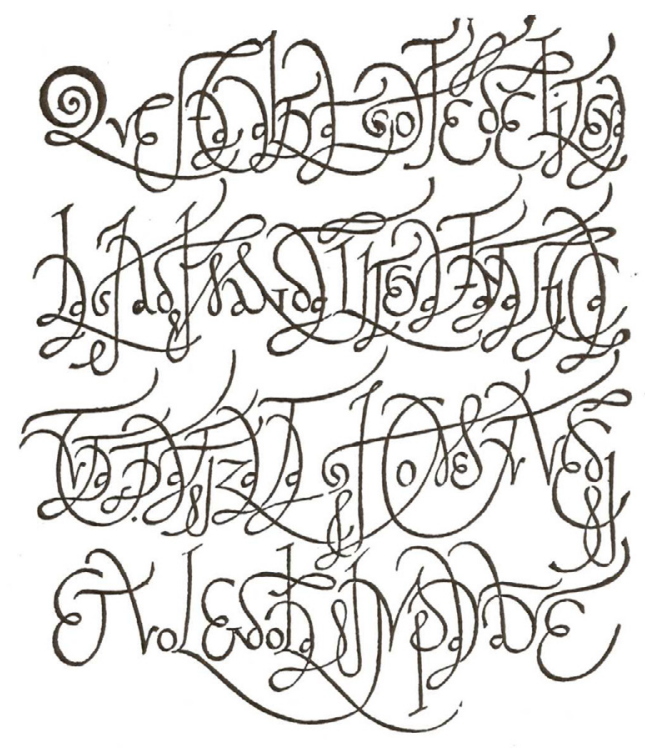

Fig. 7. La obra itálica. Caligrafías con los bucles de Tagliente (1535). 
Aldo Manuzio en Italia creó los caracteres itálicos o cursivos, que seguían también un rasgo de la escritura manual: la "cursividad". Cuanto más rápido escribimos, las letras se inclinan más a la derecha. Y si todos los caracteres eran dibujados bajo el modelo ortogonal (el ángulo recto) y el cuadrado, los caracteres itálicos rompieron con el canon tradicional: la libertad de la mano que escribe. Así, el humanismo, fundador del Renacimiento, permanecía de algún modo en la obra gutenberguiana.

A B C DE F G H I L M

NOP QV Qu RST V

$\mathrm{XY}$ abcdefgbilmno

pqrestuxy à ads au

ad ce ciroct cla cti cto ctu

ou di éerers em fafffe $f$

fo fr fuga ge grgna go gu ii iminisll ma mem momu

nane ni nont mu us ó a q;

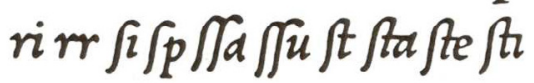

ta teti tte ttituúu um us

Fig. 8. La cancilleresca de Aldo Manuce, que incluye 68 ligaduras (1501).

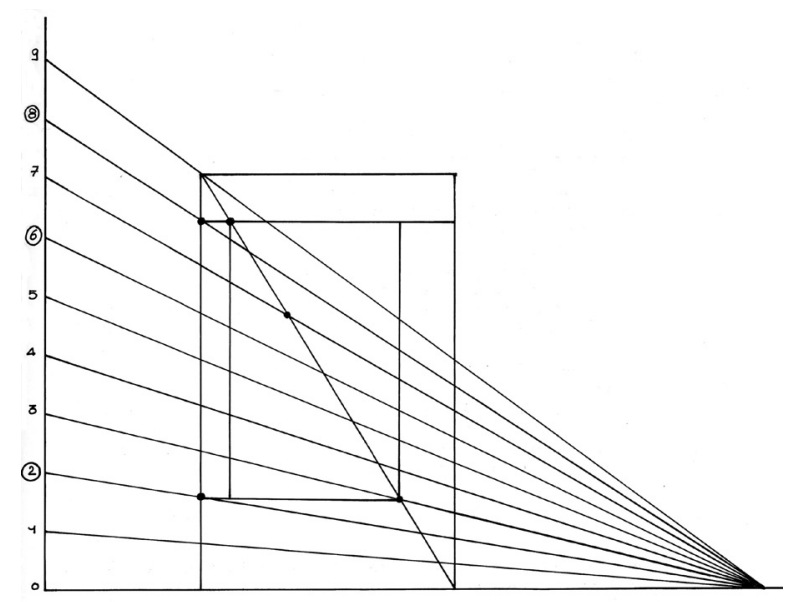

Fig. 10. Esquema de Rosarivó inspirado en la regla de oro para la compaginación libresca renacentista.

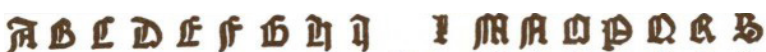

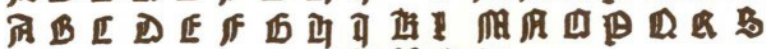

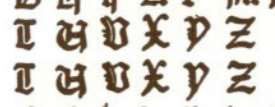

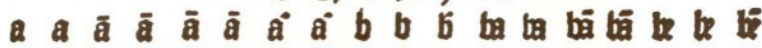

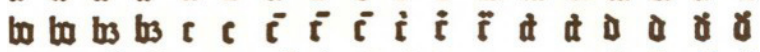

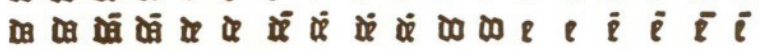

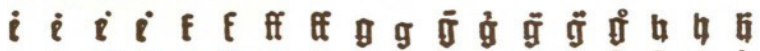

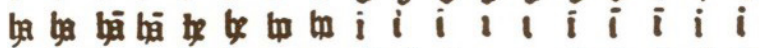

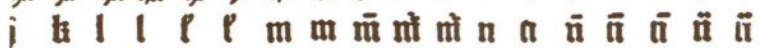
D 0 ○

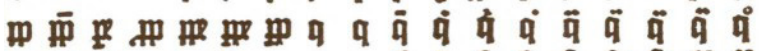
क मैं

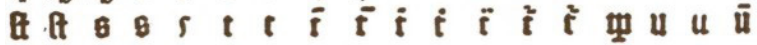

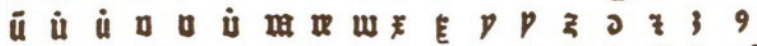

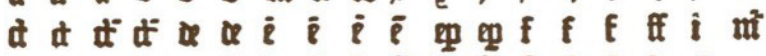

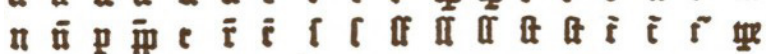
น

Fig. 9. Censo de los tipos que constituyen la caja de Gutenberg, incluyendo logotipos.
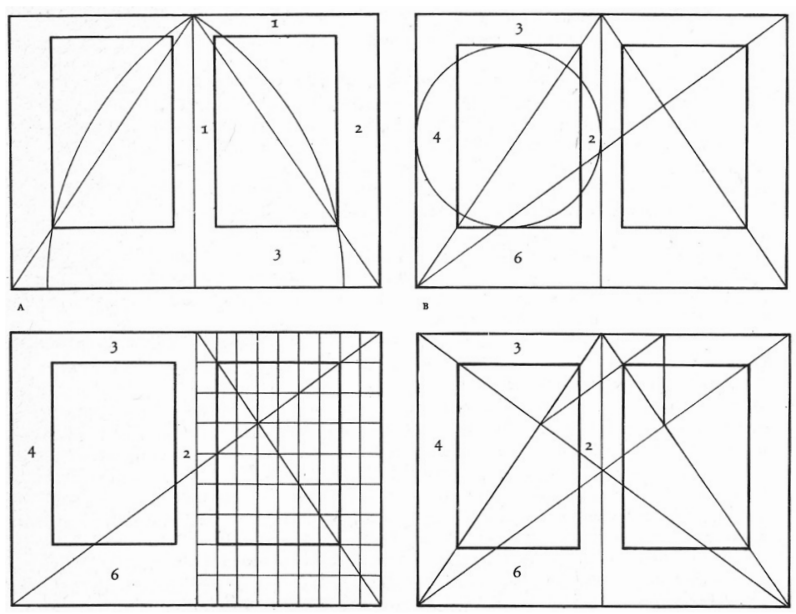

Fig. 11. Diversas pautas de compaginación. 


\section{El efecto Gutenberg}

La invención de la tipografía tuvo un eco cultural en toda Europa. La fiebre impresora se extendió por el mundo, y la enorme producción de las imprentas se estimaba inaccesible, por lo que, para poder abarcar todo el conocimiento producido por la humanidad, se consideró necesario compilarlo y sintetizarlo en obras enciclopédicas como la de Diderot o D'Alembert. El gran esfuerzo realizado por los hijos de la llustración para llevar a cabo esas monumentales empresas editoriales tenía como objetivo "la difusión del saber acumulado que, gracias al uso efectivo del arte tipográfico debía permitir el triunfo final de la razón sobre la revelación y de la ciencia sobre la superstición".

Gutenberg había inventado la comunicación masiva, la difusión del conocimiento. Y había sembrado el grafismo funcional como herramienta creadora de la tipografía que, cuatro siglos después, desembocaría en el diseño gráfico.

\section{Hijo del Arte y de la Técnica}

Hubo un momento, por cierto poco conocido, en que la imprenta de Gutenberg, pionera del diseño gráfico, se cruzó con el pionero del diseño industrial, Leonardo da Vinci, el primer artista industrial designer de la historia. Leonardo había imaginado una prensa de impresión en la que aparece por primera vez una noción de automatismo. En este proyecto, en efecto, la acción del tornillo de presión se transmite al mármol donde reposa la forma por medio de un cabestante, de modo que la composición, perfectamente accesible para las correcciones tipográficas, viene a situarse sobre la platina cuando el tornillo desciende y se libera por gravedad el muelle de retroceso cuando éste remonta.

El prototipo en madera de esta prensa se encuentra en el Clos-Lucé, junto al castillo d'Amboise, en Francia, que fue morada de Leonardo de Vinci, en la que murió, y fue convertida en museo donde se conservan los inventos mecánicos del genio.

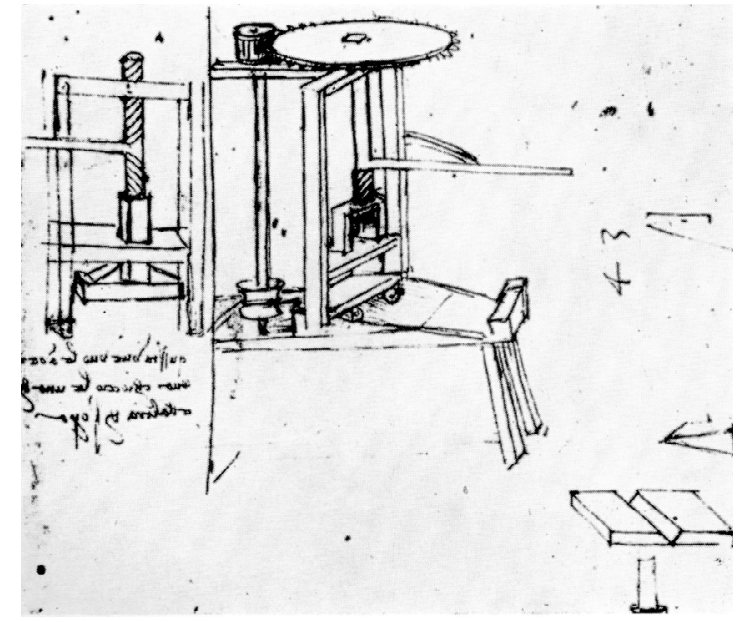

Fig. 12. Dibujo de Leonardo da Vinci para el mecanismo automático de la prensa de Gutenberg.

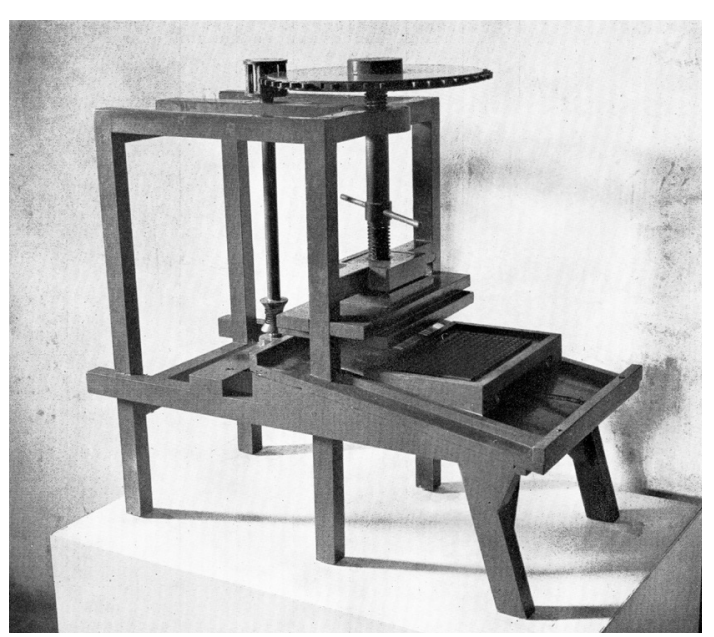

Fig. 13. Prototipo en madera del dibujo de Leonardo, que se expone en Clos-Lucé (Francia). 
Así se cruzaron los ancestros del diseño gráfico y el diseño industrial en el Renacimiento. Pero el diseño gráfico llegaría más tarde, con la invención del Cartel por los artistas gráficos. Gracias al advenimiento de la litografía en 1796 inventada por Aloys Senefelder en Praga, los artistas plásticos llevaron la verticalidad del cuadro, la tabla o el mural a la vía pública.

\section{El mundo de la Línea explota con la Forma y el Color}

Después, la escuela de la Bauhaus reúne el arte, el trabajo y la artesanía bajo la idea matriz de proyecto (el proyecto arquitectónico como referencia). $Y$ todo aquello que nace del espíritu proyectual se considera disciplina de diseño. Así fue como el grafismo funcional gutenberguiano devino diseño gráfico. 